\title{
The Concept of Ubuntu and Face in the Burundian Context: A Discourse Analysis of the Speech Acts of Requests and Apology
}

\author{
Ildephonse Horicubonye \\ University of Burundi \\ Department of English Language and Literature \\ BP: 1550 Bujumbura-Burundi
}

\begin{abstract}
This study explores the applicability of the concept of face in relation to the speech acts of requests and apology(Levinson, Brown, Levinson, \& Levinson, 1987) in the Burundian context and how the concept of Ubuntu is expressed in these speech acts. To this end, it analysed data collected from NINDE? (who is she/he?), a popular TV show in Burundi. Results indicate that while Brown and Levinson contend that requests carry a high degree of imposition and are therefore face -threatening, requests are not always considered by Burundian speakers and addressees as face threatening, and that face is primarily a societal concern rather than individual wants. Furthermore, the concept of Ubuntu reveals that speakers care more about the group's needs than individuals'.
\end{abstract}

Keywords: Apology, face, face-threatening act, Kirundi, Negative/ Positive face, request, Speech act, Ubuntu

\section{Introduction}

As face is concerned with people's language behaviour adopted in using language in conformity with the norms and values of a given society (Ide, 1993), the claim that face relates to the individual wants(Levinson et al., 1987)cannot be applicable to all the societies. Brown and researchers of similar views on politeness contend that face consists in two kinds of desires: the desire to be appreciated by others (positive face) and the desire to be unimpeded in one's actions (negative face). This view, particularly the negative face, has been challenged by many researchers on politeness, particularly those from Asia and Africa, namely Chinese researchers (Gu, 1990; Mao, 1994), a Japanese (Ide, 1993)and an African researcher (Nwoye, 1992). They argued that face as defined by Brown is applicable only to Western languages and is not appropriate to the analysis of non-Western languages. These researchers proposed that face is primarily the concern of the society rather than the individual wants, and is made applicable through its use by individuals' language (Gu, 1990; Ide, 1993; Mao, 1994; Matsumoto \& Ekman, 1989). They have therefore called this face, face group defined as the individual's desire to behave in conformity with the culturally expected norms of behaviour that are institutionalised and sanctioned by society. Contrary to the individual's desire to be unimpeded in his action as proposed by Brown, there is a need for a member of the group or the society to be accepted by other members of the society.

This concept of group face is in line with the concept of Ubuntu that is found in Sub-saharan countries. It refers to certain values that are expected from a human. It is an expression of human dignity, unselfishness and of mutual support (Cilliers, 2008) and it encompasses all the good qualities of a human being. Ubuntu is the concept which embodies human interaction in various contexts. This is the reason why all the human interactions in these communities are guided by this concept of Ubuntu (Nussbaum, 2003). This study was conducted to explore the applicability of Levinson et al's politeness theory in relation to the speech acts of requests and apology in the Burundian society, to determine whether Burundians care more about the individual or social dimension of face and how face and Ubuntu are expressed in the realisation of the speech acts of requests and apology.

\section{Related Literature}

\subsection{Ubuntu}

The concept of Ubuntu has been approached differently as the available literature shows, but the main idea put forward by several scholars is the potential for being human and thus valuing the good of the community above self-interest. Ubuntu consists in striving to help people in the spirit of service, showing respect to others and being honest and trustworthy (Chaplin, 2006). Ubuntu is described as a term used to pick out a constellation of value claims and moral normative requirements to be entailed by them(Gade, 2012). Practically, Ubuntu serves as the concept of interrelationship and interconnectedness which embodies human interaction in various contexts. 
Thus, human interaction requires that interactants select language that would fit in those different contexts. Garmon \& Mgijima (2012) observed that, communicating effectively requires the basic underlying concepts upon which the language and communication practices depend. For this purpose, all the human interactions in these communities are guided by this concept of Ubuntu and the values of Ubuntu are expressed through the language we use in our everyday communication (Nussbaum, 2003).

A clear illustration of this language use is given by the Zulu maxim umuntu ngumuntu ngabantu (Ramose, 1999, p. 49) translated in English as "people are people through other people". This maxim demonstrates the perception of self within the concept whereby individual members of the society learn to act toward each other with as much concern as they would have for themselves (Garmon \& Mgijima, 2012).Likewise, Kirundi has a similar phrase that expresses the same concern that is rendered by this expression umuntu ni uwundi, "a person is a person because of others". All these expressions mean that the individual's whole existence is relative to that of the group and that if the individual is to survive, s/he should work toward the survival of the group(Op. Cit.).

Ubuntu embodies the idea of group solidarity, compassion, respect and human dignity. This is illustrated through the African expression of Ubuntu that says: "your pain is my pain, my wealth is your wealth, and your salvation is my salvation". This illustrates how much the idea of community is given a very important consideration in African societies. People share even in period of pain. Ubuntu is bestowed upon any human who has the qualities of being human regardless of her/his status. When we want to give high praise to someone in Zulu we say: $y u$, $u$ nobuntu which is also expressed in Kirundi as uуu muntu ari n'ubuntu. This can be rendered as hey, he or she has Ubuntu (Chaplin, 2006).

Through these expressions, it is meant that the moment you go outside the boundaries of ubuntu, you actually begin to be labelled as kintu (animal or a thing) as opposed to Ubuntu (Gade, 2012). In Kirundi we have the expressions urya si umuntu translated as that one is not a person or is not human, which can be also conveyed through the expression, urya muntu ntagira ubuntu translated as "that one has no humanness". Clearly, the concept of Ubuntu is the fact that is fulfilled when they care for each other in the community and in any situation.

\subsection{Face}

The concept of face was first introduced by Goffman (1967: 5) according to whom, face is "the positive social value a person effectively claims for himself by the line others assume he has taken during a particular contact". He made it explicit that face is "an image of self that others may share." Later, Levinson et al. (1987: 61) gave another definition of face that says that face is "the public self-image that every member wants to claim for himself". They maintain that face consists of two specific desires: positive face and negative face. Positive face is the desire to have one's self-image appreciated and approved of. The second desire is negative face that is the desire to be free from imposition. In interaction, speakers must do their best to avoid acts that threaten the face of their interlocutors. Levinson et al. (op. cit.) call speech acts that are intrinsically threatening face threatening acts. When speakers are using speech acts, they must try to minimise the face threat by using appropriate strategies or avoid those acts. In English, the concept of face reflects the spirit of democratic behaviour. Each individual has the freedom of action for that other people should not impede on his/her action. Everything in one's interactions focuses on self as a scale of value. A good example is the case of the speech act of advice where the first singular person is set as a scale of value. If I were you, I would not do that.

This definition of face by Brown and Levinson was challenged by many scholars who thought that it was a deviation from the concept of face. Originally, (Goffman, 1967, p. 10) said that face is on loan by the society; hence it is a public property rather than an individual ownership (De Kadt, 1998). In support to Goffman's sense of face, Gu (1990) and Nwoye (1992: 313) extended the concept to the idea of group and thus coined the concept of group face which they defined in the following terms: "an individual's desire to behave in conformity with the culturally expected norms of behaviour that are institutionalised and sanctioned by society".

In the same vein, Ide (1993) argues that Levinson et al.'s theory of politeness and the concept of face are based on a western point of view that is biased toward individualism. She advocated for a group face that seems to be related to the need for a member of the group or society to be accepted by other members of the society. The face wants in the Burundian context are related to the desire to be accepted by others. In addition, these wants are related to the desire that the family and society be appreciated through the individual's use of language in interaction. In Kirundi, the individual culturally exists in relation to the community. This is expressed in everyday language use. For example, in the speech act of advice, a speaker does not set himself/herself as a scale of value. Iyo uba uwundi if you were someone else, while in English they say if I were you. 
Another example can be illustrated by someone who has done a shameful action who would say: ndagotse, I am being shameful and she/he is likely to add ndagokeye umuryango, I am bringing shame to the family. The same message can also be expressed through ndagokeye abavyeyi; I am bringing shame to my parents who taught me how to behave.

This is so true that when a child makes a mistake, people would say yarezwe nabi, he is badly educated or yarerewe $h e$ ?Where was he brought up? We can therefore say that in Kirundi, an individual cares about his/her self-image or self-respect to safeguard the image or respect of a whole society. In Kirundi, politeness is the cornerstone of cultural education and moral conduct. Burundians believe that the best gift they can offer to their children is to teach them how to speak politely to people. As Zuure \& de La Boullaye (2015) observed, "Someone who does not know how to choose his/her words is not polite". Thus, before saying something, one is advised to sift his words and use those that are well chosen. The following Kirundi saying illustrates it 'Ntakuvuga ibirungitswe n'umuyaga'. Translated literally as 'do not say that which is sent by the wind', it means that one should think first about what s/he is going to say.In this regard, Ethel quoted in Albert (1964) noted that "a well brought up Murundi would suffer agonies of shame in the presence of the naked truth and would hasten to provide the aesthetic coverings called for by the cultural value system". This is to show that Burundians care more about the community than they care for themselves. Therefore, in the Burundian context, face is community-based rather than individual- oriented.

\subsection{Requests}

English and Kirundi requests both have the three levels of directness that have been proposed by the cross-cultural speech act realisation project (Blum-Kulka, House, \& Kasper, 1989). The latter include, direct, conventionally indirect and non-conventionally indirect. Let us illustrate this with the following examples from Kirundi:

\section{Direct}

Imperative: Mesera izi mpuzu. (Wash for me these clothes) Wash these clothes for me.

Explicit performative: Nifuza kugenda I Gitega. (I wish to go to Gitega) I would like to go to Gitega.

Hedged performative: Nifuza kubasaba ko mwontiza umuduga aho nigira.(I wish to ask you that you can lend me a car where I want to go). I would like to ask whether you could lend me a car; I need to go to do some errands.

Goal statement: Ndabaherekeze mu gisagara?(That I go with you in town?). Can I go with you to town?

Want statement: Nifuza ko mwonshikana mu gisagara. I wish that you take me to town. I would like a ride to town.

Conventionally indirect

Query preparatory: ability or permission: Urashobora kuntiza ikaramu? (You can lend me a pen?) Can you lend me a pen?

Query preparatory: availability: Woba ufise amahera? (You would have some money?) Would you have some money on you?

\section{Non-Conventionally indirect}

Question hint: Woba ugiye I muhira? (You would go home?) Are you going home?

Statement hint: Uraziko ata karamu nazanye? (You know that there is no pen I brought?) Doyou know that I did not bring any pen?

There are other uses of requests in Kirundi, such as the use of a negative form in the statement of request, which are not given here.

Example:

Ntimwoshobora kundangira aho isoko iri? (You cannot show me where the market is?) Could you show me where the market is?

Normally, a speaker should choose to use the directness or the indirectness in requests depending on the status of the interactants, but in many situations, it is not the case. Unlike English, Kirundi most often uses a negative form in requests. In English, the use of the negative form can be interpreted as an imposition on the addressee because the expected response should be positive. On the contrary, Kirundi speakers assume that there is a strong bond between speakers and addressees. Therefore, people believe that any kind of response is a sincere one. Also, as the saying goes umugabo umumwera ubwanwa kugira azokumwer ubundi (literally translated as "you shave the beard of a man so that he could shave yours)", which means that "a good turn deserves another"), they believe that people are interdependent and there should thus be no requests that are imposing on the addressees.

Another difference between English and Kirundi requests that is very important is their semantic structure. The semantic structure of English requests is described in the following pattern (Blum-Kulka et al., op. cit. :159):

(1) I say I want you to do something good for me

(2) I say this because I want you to do it

(3) I think you do not have to do it 
(4) I do not know if you will do it"

The semantic structure of requests in English is the same for all the levels of directness. The only difference that is found is the scales of politeness that the speaker uses.

In direct requests, the addressee's face threat is very high while in conventionally indirect and non-conventionally indirect the face-threat goes decreasing. From this semantic structure, it is clear that English speakers attend very much to one's freedom of action. In requests, speakers want their needs satisfied, but at the same time they want the interests of the addressee to be safeguarded.

In Kirundi, the semantic structure is described in these patterns (Horicubonye, 2005:92):

(1) I say I want you to do something good for me

(2) I say this because I want you to do it

(3) I think you will do it because I will do the same for you

(4) I know that if you do not do it, it is because you cannot do it.

As it can be observed in the illocutionary purpose (3) I think you will do it because I will do the same for you, Kirundi values are community-based. Kirundi speakers express the idea of complementarity rather than individual needs. It is, therefore, here that English and Kirundi requests differ despite their similarity in their levels of directness. This is explained by the fact that in African cultures and specifically in the Burundian, there is mutual assistance between individuals. Thus, requesting something from someone is not face-threatening.

\subsection{Apology}

People apologise when they assume they have caused some damage to the addressee or a third party. They therefore use apology to establish the relationship between the interactants. Depending on the gravity of the damage, people use different politeness forms. For, example, they may use :I am sorry, I am very sorry about..... Most often, apologisers have to add some more elements to explain how and why the damage happened and to attest that they would never do that again or that they would repair the damage. In fact, the elements that are likely to be used are dictated by the mood of the apologiser, the seriousness of the damage, and the circumstances in which the damage occurred. People may also apologise even when there is no damage caused, but just to be polite. It is, for example, the case when one interrupts people's conversation, or when one is asking for information from a stranger; or when one is asking for passage in a crowded bus or hallway. In such circumstances, no damage has been caused, but one has to apologise in order not to appear rude. In this case, the speaker may use excuse me... In English, people may also use the expression I beg your pardon, when they want their interlocutor to repeat what has been just said.

In Kirundi, people also apologise in the same circumstances as those enumerated above. Different contexts call for different expressions that are used. In case the speaker has caused some damage to the addressee, s/he is likely to say: Murambabariral mbabarira (you suffer for me) meaning please forgive me. Ndasavye ikigongwe (I beg pardon), ndasavye imbabazi (I beg forgiveness). Most often, people would add sinzobisura (I will not repeat it) I will not do that again or sinabigize n'ibigirankana (I did not do that on purpose). When a person interrupts a conversation or when he coughs or sneezes while delivering a speech he would say murantunga (you be my master, which simply means I am sorry) or when he makes a lapsus linguae in his speech, he is likely to say: murantunga munkize/ mumburane (you be my master and keep my life safe/ plead for me). The meaning behind murantunga is that a master has normally to tolerate his servant's mistakes. As for murantunga mumburane, the speaker means that not only does one's master tolerate his servant's mistakes, but s/he can also plead for him when s/he has offended someone else. A master and his servant are in a form of social contract like a lawyer and his client. These two last expressions originated from the fact that someone who talked about the king or any other high ranking authority using inappropriate words (Kudedemba) was killed. From that time, a person who makes a lapsus linguae would apologise in order not to have the same capital punishment. This is why a speaker would prefer to be a servant and have his life safe. In the same vein, Hymes \& Gumperz (1972) observed correctly that to procure a gift and protection from a superior, to obtain a favourable judgment in a court case; in short to survive and to succeed is everybody's concern. While the English and Kirundi expressions for apologies seem to be similar at the surface structure, their semantic structure differs.

The semantic structure for the expression I am sorry or I apologise is as follows in English:"

(1) I know I did something bad to you.

(2) I feel bad towards you because of this.

(3) I want you to know I want to compensate for it.

(4) I do not know whether you will accept that (Wierzbicka, 2003) 
As can be seen from the above examples in English, the speaker is an agent while apologizing. However, Kirundi apology operates otherwise. In Kirundi, the apologiser is a patient, not because he thinks he does not feel bad towards the addressee, but because he thinks he cannot do enough to make amends for the damage he has caused.

This can be noted in the use of the verb $k u$ - babar-a(to suffer) with the derivative suffix -ir- that indicates that the addressee has to suffer for the speaker. Then we will have $n$-babar-ir-a that means suffer for me.The meaning behind all this is that the speaker regrets what s/he has done, but s/he cannot do enough to repair the damage caused. Thus, s/he is requesting the addressee to sympathise with her/him. This expression for apology in Kirundi $n$-babar-ir-a (I am sorry) can be assigned the following semantic structure:

(1) I know I did something bad to you

(2) I feel bad towards you because of this

(3) I know I cannot do enough to make you feel good

(4) I say suffer for me since I cannot suffer in your place.

The apology expression murantunga munkize (meaning I am sorry) can be assigned the following semantic structure:

(1) I know I did something bad to you.

(2) I feel bad towards you because of this

(3) I know I cannot do enough to make you feel good

(4) I say I am entirely at your mercy.

The difference between English and Kirundi apology expressions lies in the illocutionary purpose. While in English, the illocutionary purpose (3) is to compensate for the damage, in Kirundi the illocutionary purpose (3) is to recognise that the damage cannot be compensated for.

\section{The Use of the Concepts of Ubuntu and Face in Requests and Apologies in the Burundian Context}

\subsection{Data Collection and Analysis Procedures}

The present study is based on a TV and radio programme entitled NINDE?(Who is s/he?) that depicts the Burundian society, especially the rural areas. The focus was on the videos that aim to give moral lessons drawn from the bad behaviour of people who do not behave according to the Burundian norms and values. 10 videos were visualised to collect data related to the speech acts of apologies and requests used. The data were analysed following the concepts of face (Goffman, 1967; Levinson et al., 1987; Mao, 1994; Nwoye, 1992) and Ubuntu (Chaplin, 2006; Gade, 2012; Sibanda, 2014). The collected data were also analysed based on the contexts in which they were used. The analysis of the data yielded by the discourse analysis was based on many factors, namely the context in which they were used, the speaker and the addressee, the social status, and the social distance. The theoretical framework that was given in the literature review was used to interpret the data that were collected. For ease of handling of the data, they were categorised following specific criteria depending on whether they were in apology or in request. The expressions selected for analysis are presented in Tables 1 and 2 below, for requests and apologies respectively.

\subsection{Use of Requests}

For the speech act of request, the data were categorized depending on the levels of directness. Most of the collected data fall into the category of the level of direct requests mainly the imperative, explicit and hedged performatives, but they were also found at the level of non- conventionally indirect requests especially in the statement hint. This can be seen from the following examples:

(1)Mpa uтисаnwa w'itabi (me give fire of cigarette), which means “Can I have a cigarette lighter?"

(2)Ntiza umuhoro ico nikorera (me borrow a pruning knife that I do something with it) meaning "Can I borrow your pruning knife?"

Requests 1 and 2 are imperatives that are normally expected to be more face-threatening, but given that almost all the requests collected are at the level of direct request, it is assumed that it is the common way of using the speech act of request in Kirundi. Zuure \& de La Boullaye ( op. cit.) observed that Burundians are careful about their use of language. Contrary to Levinson et al's (op. cit.) face where the face threat is very high in direct requests, in the above examples, the level of imposition is low because what the speaker is requesting is something that people request so often that it has become like a matter of routine. This has been corroborated by Nwoye (op. cit.), when he says that among Igbo, exchange of cooked food and culinary ingredients is rampant among and between neighbours and carries no imposition. Also, in the Burundian context, it is assumed that you can only request assistance from a reliable person, and that you will eventually reciprocate the assistance at another time. This can be maintained by the illocutionary purpose (3) I think you will do it because I will do the same for you.

Therefore, if you do not do it, it is because you cannot do it as in the illocutionary purpose (4). Most of the requests used were at the level of direct requests mainly in the explicit and hedged performatives. 
This also applies to the following requests:

4) Narinje ngo muntabaze uduharage dukeyi (I came that you me help with beans a little), which means"I wonder whether you could assist me with some beans".

(5) Untabare ungurane udufaranga

"You me help you me lend some money", meaning "I wonder whether you could lend me some money".

According to Levinson et al., these requests are face- threatening to the addressee because in the western culture, banks are everywhere and getting a loan is easy. This entails that one does not have to bother her/his neighbours in requesting such services. On the contrary, these services are scarce in the Burundian context and probably in other African countries. Thus, asking a neighbour for these commodities was not considered as face-threatening as this quotation describing these realities says it very well"Poverty was foreign. It never was considered repugnant to ask one's neighbours for help if one was struggling. In most cases there was mutual assistance between individuals, tribes, chiefs and kings; in spite of wars"(Samkange, 1980: 89).

(7)Ntimwompa amacupa atatu nkazobaha amahera ngurishije impene (me not give bottles three of beer I will give money I sell a goat), meaning "Could you give me three bottles of beer that I will pay back when I sell a goat".

(8)Narinje kubasaba ngo muntize umwana aho amperekeza (I came to you ask that you lend me a child somewhere she me accompanies), which means "I came to ask whether you could let your child help me carry something".

(9)Narinje kubabwira ngo muze mundondere akayoga nzoterekera abakwe mu kwezi kuza (I came to you tell that you will you me look for beer there will be payment of the dowry in the month coming), which means "I came to ask whether you could bring me a jug of beer for the party of the payment of the dowry".

Mostly, the above expressions carry the same meaning of mutual assistance in the Burundian context with a few exceptions. For example, in (3) Muraduha ku gahembo (you will us give on the food you are given for lunch), which means "Can we share the food you are given for lunch?", the context in which this utterance was drawn from shows that this utterance is not only face- threatening to the addressee, but it also goes against the expected norms and values of a Burundian adult. As mentioned above, self-invitation for food is something that is not tolerated for adults even if it was in period of famine. A person who does something like this was considered as good for nothing. The title of the video in which this utterance was taken from is ubwo s'ubuntu (this is not humanness). The context reads as follows: it was in a period of food shortage and a woman went to work for food to take home, but she left her husband and children at home. As she was fed at the place of work, at lunch time, her husband took his two children and went at her place of work. On his arrival, he said muraduha ku gahembo (you will us give on the lunch you are given) meaning can we share the food you are given for lunch? Although Burundians are expected to share food with guests; ntawimana indya zihiye (noone refuses to give food cooked) meaning never refuse to share a meal with guests, they discourage people who behave idly like this man. This is a good example of the notion of group face because the act is not only damaging for the individual but also for the whole community. Through this utterance, both his wife and the host family were embarrassed by the behaviour of this man. As the Kirundi saying goes umuntu arasonza akigumya meaning one should refrain from displaying her/his hunger. Since in the traditional Burundi, people used to depend mainly on agriculture for their livelihood, someone suffering from lack of food would be considered as lazy. People will therefore suffer agonies of shame before the naked truth (Hymes\&Gumperz, 1972:76) and would never disclose that they are hungry even if it is a custom to assist one another.

The request in example (6) Narinje ngo mumpe vya biharage yababikije ari mu bitaro, which means "I came to ask whether you could give me the beans my wife entrusted you" is also unusual given the situation in which it is uttered. Here the husband used to sell everything that they had at home. In response, his wife decided to go and hide some grains of beans at her mother's. Her husband came to know about that and he decided to go and ask for it pretending that his wife was admitted into the hospital. As the title of the video is ubwo s'ubuntu (this is not humanness), the seriousness of the violation of face here is very high. This is explained by the fact that the status of one's mother-in-law as social distance is concerned is even greater than that of one's mother. Thus, this man has threatened the face of her mother-in-law who could not refuse to respond favourably to the request even though she knew the man was lying. In this example, the speaker has not only threatened the addressee's face, but has also violated the social norm and value. This is thus a good example of group face. There are other instances in which the speaker uses non- conventionally indirect requests. These are examples,

(10)Amapfa araha agiye kutumara (this famine is going to us finish) meaning "I would like to ask you something that I can cook, I am starving";

(11)Singira n'akunyu (I do not have and salt) meaning "Could you lend some salt?"

(12) Aha naringiye kurondera utubabi none ndabuze (here I was going to look for some vegetable but I failed to get some) meaning "Could I have some vegetable to cook?" 
(13)Inzoga iraha iraryoshe, which means, can I have some beer?

In each of the above examples, non-conventionally indirect requests that normally soften the face threat are used even though Burundians do not consider that these requests carry any imposition. This is explained by the fact that the speaker is not very familiar with the addressee. However, she or he does not hide her/his needs of the intimate things (Brown, op.cit.) to the addressee.In example (9) for instance, the speaker in requesting for food from her/his neighbour uses the non-conventionally indirect request that softens the face threat to the speaker.Even though no one will refuse to give food, people will rarely request for food because it implies that you are idle, that you do not cultivate which is badly considered in the society. In (11), the speaker is requesting for some salt. In this example, he uses the nonconventionally indirect request because this utterance is part of a list of her/ his needs. It is explained by the use of $n a$ (and) that shows that she is enumerating, otherwise requesting for salt is very commonly used. It is therefore not face threatening. Examples (11) and (12) have the same explanation as in example (9), but example (13) is less facethreatening because it is not among the intimate things that were talked about above. Burundian people think that requesting for beer is acceptable what is not acceptable is requesting for food (ntawuvumba indya).

As far as the concept of Ubuntu is concerned, requesting something from someone is considered as an expected behaviour among Burundians. This is illustrated by the Kirundi expression umuntu ni uwundi meaning that people are interdependent. Thus, in the examples (4) narinje ngo muntabaze uduharage dukeyi (I wonder whether you could assist me with some beans),(5) Untabare ungurane udufaranga (I wonder whether you could lend me some money) and (8) narinje kubasaba ko mwontiza umwana aho amperekeza (I came to ask whether you could let your child help me carry something), these requests express the idea of solidarity, mutual assistance and caring for each other. Burundians use these expressions without any idea of imposition on the addressees. Since Ubuntu stresses the importance of community, solidarity, caring and sharing, requesting becomes an act that is likely to be performed without too much weighing its imposition on interactants. This is clearly shown by the illocutionary purpose (c) above "I think you will do it because I will do the same for you". This is also illustrated by this Kirundi phrase, "umugabo umumwera ubwanwa kugira azokumwere ubundi" (that can be translated in English as a good turn deserves another. Another clear illustration of this language use is given by the Zulu maxim umuntu ngumuntu ngabantu(Cilliers, 2008) translated in English as "people are people through other people". Likewise, Kirundi has a similar phrase that expresses the same concern that is rendered by this expression umuntu ni uwundi (a person is a person because of another). All these expressions indicate that the individual's whole existence is relative to that of the group and that if the individual is to survive, he/ she should work toward the survival of the group (Garmon \& Mgijima, op. cit.).

In some contexts, Burundians would rather prefer to starve instead of asking for cooked food. This would be considered as humiliating for the family, which could be qualified of lazy. Doing this would be therefore violating the social norm. This is illustrated by example (3) murampa ku gahembo"can we share the food you are given for lunch" that is considered as self invitation for food which is impolite in Kirundi. People have to refrain from showing that they are hungry. This becomes an insult for the family that is unable to feed its members. This is only done by beggars and these latter are considered as destitutes in the society. In example (6), narinje ngo mumpe vya biharage yababikije" I came to ask whether you could give me the beans my wife entrusted you", the husband has violated the social value. One is not supposed to discuss about food with his mother-in-law. This is interpreted as lack of respect to himself and her motherin-law. While Levinson et al. (Op. Cit.) contend that requests carry a high degree of imposition and therefore face threatening, the results from these data show that requests are not considered by Burundian speakers and addressees as threatening. However, there are situations which called for imposition for example when social norms and values were violated as in examples 3 and 6 above.

\subsection{Use of Apologies}

Conversely to the speech acts of requests that are most of the cases not inherently face threatening for the interactants and third parties, the speech act of apology is face threatening to the speaker because apologies involve loss of face for him or her because it involves admitting that the speaker has caused a damage to the addressee. The illocution indicating devices for the speech acts of apology are not many, but they are used in different situations and according to the seriousness of the violation. In this study, the researcher identified the following formula used in different situations:

(1)Ndasavye imbabazi (I beg forgiveness) this is the most commonly used semantic formula for the speech act of apology. It is used in all the situations regardless of the seriousness of the violation.

(2)Ndagarutse muri mwebwe mungirire ikigongwe (I come back among you (people) so that you could forgive me), which means I come back among you (people) so that you could forgive me.

This is said when the seriousness of the violation is very high. This was said in a context where a man sold the land of the family, the house and the goats, and he left the family to go to town with another woman. After sometime, the money was finished, and the woman left him and he was obliged to go back home. 
Someone who had behaved like this was disqualified from the quality of being human, from other people (gucibwa ти Bantu). Through this expression, it means that someone has gone outside the boundaries of Ubuntu, you actually begin to be labelled as - kintu(animal or thing) as opposed to ubuntu (Gade, 2012). To be considered again as someone who has Ubuntu will be a difficult if not impossible process.

(3)Ndiko ndamaramara (I became shameless) the speaker self-denigrates because of the violation he committed.

(4)Ngirira ikigongwe sinzosubira (sympathise with me I will not do that again), meaning I beg your forgiveness, I will not do that again. The speaker expresses regret and promises not to ever do the same again.

(5) Mbabariranagize uko ubukene bugize (me suffer for I did as poverty does), which means please forgiveme I did this because of poverty. The speaker expresses regret and gives an explanation for committing the act. In Kirundi, the illocutionary purpose (c) the expression of apology is to recognise that the damage cannot be compensated for, so, s/he invites the addressee to suffer in his place and thus forgive her/him.

(6)Ndabamaramaje I am putting shame on the whole family and (7)Ndagokeye umuryango meaning I am putting shame on the family.Moral responsibility is corporate, that is even the wrong done by one individual has ripple implications for the whole clan or even the whole community(Gade, 2012: 493) In Kirundi, this is expressed through the use of proverbs like: umuryambwa aba umwe agatukisha umuryango(a dog eater is one he puts shame on the family meaning even if a wrong doer is only one person, he puts shame on the whole family). The apologizer is not very much worried about his face but the face of the family or the society that will be damaged. But he has to apologise because if he violates the social norms he loses the quality of ubuntu and he/she is considered as a 'kintu' animal or object. He is therefore not a member of human beings community because the individual culturally exists in relation to the community. This is expressed through this apology 'ndagarutse muri mwebwe mungirire ikigongwe"meaning I come back among you (people) so that you could forgive me. In the apology expression ndagokeye umuryango, the apologizer wants to show that he did not live up to the parents' education (indero runtu). This means that parents have to educate their children to become respectful, compassionate, to maintain dignity even in difficult situations.

\section{Conclusion}

The present study examined the concept of face proposed by Levinson et al. through the use of the speech acts of requests and apologies in a Burundian context. Results indicate that even if face for individuals can be observed in the Burundian society, face wants are geared towards the community. This is mainly due to the fact that Burundians and Africans at large advocate for mutual assistance and that people are interdependent. These results are in line with what other researchers' findings in Igbo (Nwoye, 1992), Zulu (De Kadt, 1998) and Chinese (Gu, 1990) languages. Exploring the concept of Ubuntu that embodies the idea of group solidarity and compassion indicates that the use of the speech acts of requests and apologies maintained that people are people through other people, and that collective needs override individual wants, confirming previous research findings of studies conducted mainly on Zulu, namely, (Chaplin, 2006), (Gade, 2012) and (Garmon \& Mgijima, 2012)

While this study has answered the research questions that guided it, it has raised other questions worth considering in follow-up studies. For instance, the concept of Ubuntu seems to be owned by many African communities. It would be interesting to make a study on a broader scale in Africa in order to find out how these concepts would be expressed in other speech acts. Furthermore, the plays from which the data were collected address a target audience and seem to be located in the heart of Burundi -with a typical Burundian family in mind. Conducting a similar study involving other plays with a different target audience may bring more insights into the use of these speech acts. Theatre groups, plays that particularly address the youth could be a case in point.

All in all, this study has demonstrated that the use of requests and apologies in Burundi differs from the model proposed by Levinson et al. and has accounted for it. It has also shown what is embodied in the concept of Ubuntu in a Burundian setting. This study complements other studies which have investigated the model in other constellations, which is its modest contribution to the field.

\section{References}

Albert, E. M. (1964). "Rhetoric,"“Logic," and "Poetics" in Burundi: Culture Patterning of Speech Behavior1. American Anthropologist, 66(6_PART2), 35-54.

Blum-Kulka, S., House, J., \& Kasper, G. (1989). Cross-cultural pragmatics: Requests and apologies (Vol. 31). Ablex Pub.

Chaplin, K. (2006). The Ubuntu spirit in African communities. Retrieved January, 30, 2015. 
Cilliers, J. (2008). In search of meaning between Ubuntu and Into: Perspectives on preaching in post-apartheid South Africa. In Eigth International Conference of SocietasHomiletica, Copenhagen, Denmark. Citeseer.

De Kadt, E. (1998). The concept of face and its applicability to the Zulu language. Journal of Pragmatics, 29(2), 173191.

Gade, C. B. (2012). What is Ubuntu? Different interpretations among South Africans of African descent. South African Journal of Philosophy, 31(3), 484-503.

Garmon, C. W., \&Mgijima, M. (2012). Using Ubuntu: A new research trend for developing effective communication across cultural barriers.

Goffman, E. (1967). Interaction Ritual: Essays on Face Behavior. Pantheon Books.

Gu, Y. (1990). Politeness phenomena in modern Chinese. Journal of Pragmatics, 14(2), 237-257.

Hymes, D. H., \&Gumperz, J. J. (1972). Directions in sociolinguistics: The ethnography of communication. Holt, Rinehart and Winston.

Ide, S. (1993). Preface: The search for integrated universals of linguistic politeness. Multilingua-Journal Of CrossCultural And Interlanguage Communication, 12(1), 7-12.

Levinson, P., Brown, P., Levinson, S. C., \& Levinson, S. C. (1987). Politeness: Some universals in language usage (Vol. 4). Cambridge university press.

Mao, L. R. (1994). Beyond politeness theory: 'Face'revisited and renewed. Journal of Pragmatics, 21(5), 451-486.

Matsumoto, D., \& Ekman, P. (1989). American-Japanese cultural differences in intensity ratings of facial expressions of emotion. Motivation and Emotion, 13(2), 143-157.

Nussbaum, B. (2003). Ubuntu: Reflections of a South African on our common humanity. Reflections: The SoL Journal, 4(4), 21-26.

Nwoye, O. G. (1992). Linguistic politeness and socio-cultural variations of the notion of face. Journal of Pragmatics, $18(4), 309-328$.

Ramose, M. B. (1999). African philosophy through ubuntu.

Samkange, S. J. T. (1980). Hunhuism or Ubuntuism: A Zimbabwe indigenous political philosophy.

Sibanda, P. (2014). The dimensions of 'Hunhu/Ubuntu'(Humanism in the African sense): The Zimbabwean conception. Dimensions, 4(01).

Wierzbicka, A. (2003). Cross-cultural pragmatics. Walter de Gruyter Inc.

Zuure, B., \& de La Boullaye, H. P. (2015). L'âme du Murundi. Beauchesne.

Appendice 1: Expressions Analysed for Requests

\begin{tabular}{|l|l|l|l|}
\hline Expression & Meaning & $\begin{array}{l}\text { Videos } \\
\text { Occurrence } \\
\text { similar } \\
\text { expressions }\end{array}$ \\
\hline 1.Mpa umucanwa w'itabi & Can I have a cigarette lighter? & $1,4,6,10$ & 4 \\
\hline 2.Ntiza umuhoro ico nikorera & Can I borrow your pruning knife & 4,7 & 2 \\
\hline 3.Muraduha ku gahembo & Can we share the food you are given for lunch?", & 4 & 1 \\
\hline $\begin{array}{l}\text { 4Narinje ngo muntabaze uduharage } \\
\text { dukeyi. }\end{array}$ & $\begin{array}{l}\text { I wonder whether you could assist me with some } \\
\text { beans }\end{array}$ & 5 & 1 \\
\hline 5 Untabare ungurane udufaranga. & I wonder whether you could lend me some money". & 6,7 & 2 \\
\hline $\begin{array}{l}\text { 6. Narinje ngo mumpe vya biharage } \\
\text { yababikije ari mu bitaro }\end{array}$ & $\begin{array}{l}\text { I came to ask whether you could give me the beans } \\
\text { my wife entrusted you }\end{array}$ & 1 & 1 \\
\hline $\begin{array}{l}\text { 7.Ntimwompa amacupa atatu nkazobaha } \\
\text { amahera ngurishije impene }\end{array}$ & $\begin{array}{l}\text { Could you give me three bottles of beer that I will } \\
\text { pay back when I sell a goat". }\end{array}$ & 1 & 1 \\
\hline $\begin{array}{l}\text { 8.Narinje kubasaba ngo muntize umwana } \\
\text { aho amperekeza }\end{array}$ & $\begin{array}{l}\text { I came to ask whether you could let your child help } \\
\text { me carry something". }\end{array}$ & 3,5 & 2 \\
\hline $\begin{array}{l}\text { 9. Narinje kubabwira ngo } \\
\text { muzemundondere akayoga nzoterekera } \\
\text { abakwe mu kwezi kuza }\end{array}$ & $\begin{array}{l}\text { I came to ask whether you could bring me a jug of } \\
\text { beer for the party of the payment of the dowry". }\end{array}$ & 7,9 & 2 \\
\hline $\begin{array}{l}\text { 10.Amapfa araha agiye kutumara } \\
\text { I1.Singira n'akanyu }\end{array}$ & $\begin{array}{l}\text { I would like to ask you something that I can cook, I } \\
\text { am starving }\end{array}$ & 2 & 1 \\
\hline $\begin{array}{l}\text { 12.Aha naringiye kurondera utubabi none } \\
\text { ndabuze }\end{array}$ & Could youlend some salt?" & 2 & 1 \\
\hline 13Inzoga iraha iraryoshe & Could I have some vegetable to cook?" & 2 & 1 \\
\hline
\end{tabular}




\section{Appendice 2: Expressions Analysed for Apology}

\begin{tabular}{|l|l|l|l|}
\hline Expression & Meaning & Source & $\begin{array}{l}\text { Number of } \\
\text { occurrence }\end{array}$ \\
\hline 1.Ndasavye imbabazi & I beg forgiveness & Videos1, 3,5 etc & 3 \\
\hline $\begin{array}{l}\text { 2.Ndagarutse muri mwebwe mungirire } \\
\text { ikigongwe }\end{array}$ & $\begin{array}{l}\text { means I come back among you } \\
\text { (people) so that you could forgive me }\end{array}$ & 1 & 1 \\
\hline 3.Ndikondamaramara & I became shameless & 4 & 1 \\
\hline 4.Ngirira ikigongwe sinzosubira & $\begin{array}{l}\text { I beg your forgiveness, I will not do } \\
\text { that again }\end{array}$ & 3 \\
\hline 5.Mbabarir anagize uko ubukene bugize & $\begin{array}{l}\text { I am sorry I did this because of } \\
\text { poverty }\end{array}$ & $3,2,1$ \\
\hline 6.Ndabamaramaje & $\begin{array}{l}\text { I am putting shame on the whole } \\
\text { family }\end{array}$ & 3,1 & 2 \\
\hline 7. Ndagokeye umuryango & I am putting shame on the family & 1 & 1 \\
\hline
\end{tabular}

